\title{
Attitudes and Practices of University Health Education Faculty Related to Alternative Medicine
}

\author{
Roland Lamarine $^{1}$, K. John Fisher ${ }^{2}$, Vic Sbarbaro ${ }^{1}$ \\ ${ }^{1}$ California State University, Chico, California \\ ${ }^{2}$ Oregon Research Institute, Eugene, Oregon
}

\begin{abstract}
This study determined attitudes and practices, including gender differences, of university health education faculty regarding advocacy and use of alternative medicine. A random sample of health education instructors from institutions offering degrees in health education was surveyed using a written questionnaire. Health education instructors from 41 out of 48 states and territories with programs in health education responded to this survey, comprising a total of 220 usable responses. Results of this survey indicated health education instructors were more likely than the general population to use alternative medicine therapies. The majority of instructors who used such therapies reported high to moderate levels of satisfaction. Significant gender differences were uncovered regarding use, satisfaction, and advocacy for alternative medicine.
\end{abstract}

(C) 2003 Californian Journal of Health Promotion. All rights reserved.

Keywords: Complimentary and alternative medicine, health attitudes and practices, health educators, advocacy

\section{Introduction}

As the cost of affordable, accessible health care continues to exceed the grasp of many people, the lure and attraction of complementary and alternative medicine (CAM) to relieve pain and illness has increased (Cassileth, 1999; Murray \& Rubel, 1992). Recent years have witnessed a significant rise in the use of self-selected and self-administered therapies including alternative medicine (Eisenberg, 2001; Zolman \& Vickers, 1999a). Not only is the use of these therapies increasing rapidly, it is increasing notably among well-educated, affluent individuals (Eisenberg, Davis, Ettner, Appel, Wilkey, Van Rompay, \& Kessler, 1998; Zolman \& Vickers, 1999b), sometimes with serious implications for patients as well as providers (Murray \& Rubel 1992; Vickers \& Zolman, 1999).

Compared to non-users, alternative medicine devotees were better educated, more often reported lower than average health status, and were more dissatisfied with conventional medicine, which was viewed as expensive, ineffective, and disease-focused, rather than health-oriented (Astin, 1998; Ottolini, Hamburg, \& Loprieto, 1999). Conventional medical practitioners report that their patients are increasingly using alternative medicine but do not always disclose this to them (Eisenberg, Kessler, Foster, Norlock, Calkins, \& Delbanco, 1993; Fisher \& Ward, 1994; Vickers \& Zolman, 1999).

Health educators serve as disseminators of health knowledge and influence attitudes and practices of patients, which sometimes can facilitate productive doctor-patient relationships (Redwood, 2002). Since the field of alternative medicine is exceptionally broad and encompasses a myriad of therapies, it is important that health educators and other health and medical professionals receive appropriate training and scientifically based advice on both the benefits and the dangers associated with various alternative medicines (Wilson, Mills, Ross, \& Guyatt, 2002). The call for more scientific evaluation of interventions and more rigorous evidence based approaches for CAM is solidifying (Graheme-Smith, 1995; Haynes, 
1999; Sackett, et al., 1996; Fontanarosa \& Lundberg, 1998). Medical journals, such as the British Medical Journal and the Annals of Internal Medicine, have published editorials that have criticized CAM approaches and have called for CAM trials to be subject to similar rigor and scrutiny that allopathic medicine has undergone (Wilson, Mills, Ross, \& Guyatt, 2002).

Kemper (2001, p. 7), writing as a pediatrician, noted, "Few clinicians would argue with the tenet that patient-focused, humane, holistic care is the ideal of medicine. Nor would modern physicians disagree on the importance of considering a range of treatment options and using an evidence basis to select those most likely to be beneficial and least costly or harmful." There may be a gap between this philosophy and the practice of conventional medicine among physicians in family practice. Alternative medicine has begun to fill this gap, but at what price?

In recent years, there have been surveys of physician (Berman, 1998; Easthope, Tranter, \& Gill, 2000; Ernst, Resch, \& White, 1995; Gordon, Sobel, \& Tarazona, 1998; Sikand \& Laken, 1998; Silverstein \& Spiegel, 2001), dietitian (Lee \& Georgiou, 2000), and nurse (Brolinson, Price, \& Ditmyer, 2000) attitudes toward alternative medicine. A review of surveys related to alternative medicine conducted over the last five years which examined gender differences in the use of alternative medicine produced mixed results with five studies showing no significant gender differences in use (Elder, Gillcrist, \& Minz, 1997; Krauss, Godfrey, Kirk, \& Eisenberg, 1998; Langmead, Chitnis, \& Rampton, 2002; Rhee \& Spaeth, et al., 2002; Weiss, Takakuwa, \& Ernst, 2001) and three studies showing significant gender differences, in all cases suggesting women were more likely to be alternative medicine users (Cherniack, Senzel, \& Pan, 2001; Gotay, Hara, Issell, \& Maskarinec, 1999; Ni, Simile, \& Hardy, 2002). Results from these surveys have offered support as well as criticism of CAM approaches. Medical professionals are examining the role of alternative medicine in mainstream practice. Wetzel, Eisenberg, and Kaptchuk (1998) found that 75 out of the 125 U.S. medical schools offer elective courses on alternative medicine or include alternative medicine topics in required courses.

Health educators have recently proposed the integration of alternative medicine into the health education curriculum (Patterson \& Graf, 2000). In an attempt to establish a baseline of the current attitudes and practices of health education instructors towards alternative medicine, this study surveyed health education instructors from a national sample of universities to determine their attitudes and practices related to alternative medicine. The purpose of this paper is: 1) to report on a national survey of health instructor attitudes, practices, and advocacy for alternative medicine, and 2) to examine gender differences among this sample.

\section{Methods}

\section{Instrumentation}

A short written survey was developed to measure attitudes and practices regarding alternative medicine (see Appendix A). Perhaps the most challenging aspect of developing a reliable and valid instrument was in arriving at a universally acceptable definition of alternative medicine. Alternative medicine was chosen rather than complementary and alternative medicine (CAM) because the researchers were specifically interested in therapies that might be chosen instead of traditional medicine rather than as a complement to traditional practices. Many definitions for alternative medicine are present in the professional literature. For this survey the researchers attempted to standardize their definition by employing a widely cited definition (Murray \& Rubel, 1992; Segen, 1998) describing alternative medicine as "a heterogeneous set of practices that are offered as an alternative to conventional medicine, for the preservation of health and the diagnosis and treatment of health related problems: its practitioners are often called healers" (Murray \& Rubel, 1992, p. 61). In addition to this definition, the major approaches encompassed by alternative medicine, as described in the literature, were listed. 
It was clear, a priori, that no matter what definition was presented and what therapies were explicitly mentioned, there would nonetheless be questions about other therapies not specifically cited. The researchers assumed that professional health educators would be better versed in the literature than a lay audience. For this research, we defined conventional (allopathic) medicine as "medical practices and procedures commonly employed by physicians and other certified health workers."

The survey was comprised of a variety of items, which utilized a Likert scale and inquired about attitudes and practices regarding alternative and conventional medicine. In addition, based upon relationships described in the professional literature, questions were asked seeking selfreported psychological health, sexual satisfaction, serious illness, fear of recurrence for those with serious illnesses within the last five years, overall health status, and demographic data. Respondents were asked to list all therapies they had personally employed. They were also asked to list alternative therapies that merited closer scientific review for possible inclusion as part of conventional medicine.

The survey was pilot tested to establish face, content, and construct validity with instructors ( $\mathrm{n}=18$ ) at a four-year university's health education program. Based upon the pilot test, unclear items were rewritten and a second round of pilot testing resulted in appropriate validity. A split-half test for reliability produced an acceptable Spearman-Brown of $r=0.76$.

\section{Subjects}

The most recent American Association of Health Education's Directory of Institutions (AAHE, 1997) offering degrees in health education comprised the sampling frame for this study. Three questionnaires, along with a protocol for randomizing their distribution, were mailed to the chairs of all the 214 health education programs listed in the AAHE directory. After adjusting for changes in programs since the Directory was last updated, the return rate following a second mailing was $44 \%$ for a total of 220 surveys from 41 out of 48 states and territories with programs in health education. The accepting sample included approximately $40 \%$ of all health education programs in the U.S. and Puerto Rico and included a wide geographic distribution.

\section{Data Analysis}

In addition to descriptive statistics, chi-square and Pearson product-moment correlations were used to determine significant associations between variables.

\section{Results}

A total of 220 completed surveys were returned from health education degree-granting programs listed in the AAHE directory. Females comprised $54 \%$ of the respondents, while $83 \%$ reported having doctoral degrees (see Table 1). The sample had an average of 19 years (S.D.= 9.67) of work experience as health education instructors.

As Table 1 shows, our sample of well-educated health professionals reported excellent physical and psychological health. Respondents reported an average of three weekly aerobic exercise sessions lasting a minimum of 20 minutes each. Sexual satisfaction during the last year was above average at $78 \%$. Serious illness had affected $13 \%$ during the last five years and of this group, $56 \%$ had moderate to high fear of recurrence.

Advocacy for and use of alternative therapies was high across the sample. In regard to confidence in and satisfaction with conventional and alternative medicine, $95 \%$ of respondents reported moderate to high levels of confidence with conventional medicine, while $94 \%$ were somewhat or very satisfied with conventional medicine. Out of $66 \%$ of respondents who had used alternative medicine, $77 \%$ were somewhat or very satisfied with those therapies. 
Table 1

Descriptive Statistics of a Sample of 200 Health Education Instructors in USA Universities

\begin{tabular}{|l|c|}
\hline \multicolumn{1}{|c|}{ Description } & Percent \\
\hline Gender (\% Female) & 54 \\
\hline Doctorate degree (\% Ph.D.) & 83 \\
\hline & \\
\hline Health Status (Percent Reporting) & \\
\hline Physical health (excellent) & 93 \\
\hline Psychological health (good to very good) & 97 \\
\hline Sexual satisfaction (good to very good) & 78 \\
\hline Alternative Medicine Use (Percent Reporting) & \\
\hline Use alternative medicine & 66 \\
\hline Satisfied with alternative medicine & 77 \\
\hline Advocate alternative medicine use & 70 \\
\hline
\end{tabular}

In an attempt to gain a perspective on the sample's frame of reference, a number of items were included which centered on the importance of scientific evidence in substantiating claims for the efficacy of alternative medicine. Ninetythree percent said that scientific evidence was very or somewhat important in their decision to support alternative medicine, however, $22 \%$ stated that it would always or most of the time be ethical for health educators to advocate for the use of untested or unproven therapies. Furthermore, $90 \%$ reported that it was absolutely or usually essential to scientifically test all proposed new therapies.

One other finding consistent with the professional literature (Burstein, Gelber, Guadagnoli, \& Weeks, 1999) was that those who had been seriously ill within the last five years were significantly more likely to advocate for alternative medicine $\left(\mathrm{X}^{2}=12.57\right.$, df $=3, \mathrm{p}=$ .006). Another significant finding germane to this study included a significant negative correlation between satisfaction with conventional medicine and satisfaction with alternative medicine $(\mathrm{R}=-0.21, \mathrm{p}=.007)$. Also, there was a significant negative correlation between belief in the importance of scientific evidence for new therapies and advocating for the use of unproven therapies $(\mathrm{r}=-0.21, \mathrm{p}=$ $.002)$.

\section{Gender Comparisons}

Five statistically significant gender differences were uncovered regarding alternative medicine as described in Table 2. Females were significantly more likely to use, to advocate for, and to be satisfied with alternative medicine.

\section{Discussion}

\section{Limitations}

Perhaps the most fundamental difficulty confronting the researchers was to arrive at a generally recognized definition of alternative medicine that was a) broad enough so that the myriad therapies that are extant were included, but b) narrow enough so that the key criterion of being a therapy or practice not commonly included within conventional medicine, was not lost. This issue also related to the validity of the data to be collected. Survey results suggest that the vast majority of respondents understood what was and was not intended to be included within the domain of alternative medicine. 
Table 2

Gender Differences of Health Education Instructors Regarding Advocacy for Alternative Medicine

\begin{tabular}{|c|c|c|c|c|c|c|}
\hline & Gender & $\mathbf{n}$ & $\%$ & $\chi^{2}$ & df & $\mathbf{P}$ \\
\hline \multirow{2}{*}{$\begin{array}{l}\text { In your capacity as a health educator, would you advocate for the } \\
\text { use of alternative medicine? (Always/Sometimes) } \\
\text { 1. Females significantly more likely to advocate for alternative } \\
\text { medicine. }\end{array}$} & Female & 95 & 81 & & & \\
\hline & Male & 58 & 58 & 15.57 & 3 & .001 \\
\hline \multirow{2}{*}{$\begin{array}{l}\text { Have you personally used alternative medical therapies? (Yes) } \\
\text { 2. Females significantly more likely to use alternative } \\
\text { medicine. }\end{array}$} & Female & 89 & 75 & & & \\
\hline & Male & 52 & 53 & 12.74 & 3 & .002 \\
\hline \multirow{2}{*}{$\begin{array}{l}\text { How would you rate your personal experiences with alternative } \\
\text { medicine? (Very/Somewhat Satisfied) } \\
\text { 3. Females significantly more satisfied with alternative medical } \\
\text { experience. }\end{array}$} & Female & 84 & 85 & & & \\
\hline & Male & 39 & 65 & 17.00 & 3 & .001 \\
\hline \multirow{2}{*}{$\begin{array}{l}\text { How important is scientific evidence in your decision to support } \\
\text { an alternative therapy? (Very/Somewhat Important) } \\
\text { 4. Males sign. more likely to say absolutely essential for } \\
\text { scientific testing of new therapies. }\end{array}$} & Female & 101 & 87 & & & \\
\hline & Male & 92 & 94 & 12.56 & 3 & .006 \\
\hline \multirow{2}{*}{$\begin{array}{l}\text { In general, what is your level of confidence in scientifically } \\
\text { tested conventional medicine? (High/Moderate) } \\
\text { 5. Females significantly more likely to have high level of } \\
\text { confidence in conventional medicine. }\end{array}$} & Female & 115 & 97 & & & \\
\hline & Male & 92 & 92 & 14.80 & 3 & .002 \\
\hline
\end{tabular}

The use of a widely cited definition (Murray \& Rubel, 1992; Segen, 1998) along with a listing of seven broad, generally recognizable categories of alternative medical practices, provided as detailed a description as was feasible within the context of the study. Subjects were asked to list alternative therapies they had employed and also to itemize those alternative therapies they felt merited closer scientific examination as potentially effective components for conventional medicine. The list of therapies cited (see Figures $1 \& 2$ ) included items generally subsumed under the heading of alternative medicine suggesting the validity of the definition and description provided with the survey.

Another potential limitation was the relatively low percent of the accepting sample (44\%). The accepting sample appeared to be representative of the health education faculty within the United States. Based upon postmarks on returned envelopes (this was an anonymous survey), over
$85 \%$ of all states and territories with health education degree granting programs responded.

\section{Sample Characteristics}

The sample demographics suggest a preponderance $(83 \%)$ of the sample included faculty with doctoral degrees, slightly more females (54\%), and a relatively long work experience (19 year average) providing a sampling of well-educated and seasoned professionals.

\section{Attitudes And Practices Related To Alternative Medicine}

The large percentage $(70 \%)$ of respondents who indicated that they would sometimes or always advocate for the use of alternative medicine suggests an open acceptance of unproven or poorly tested therapies. This level of acceptance may warrant further scrutiny. Since $66 \%$ of the sample reported trying alternative medicine, it appears as though they are practicing what they preach. 


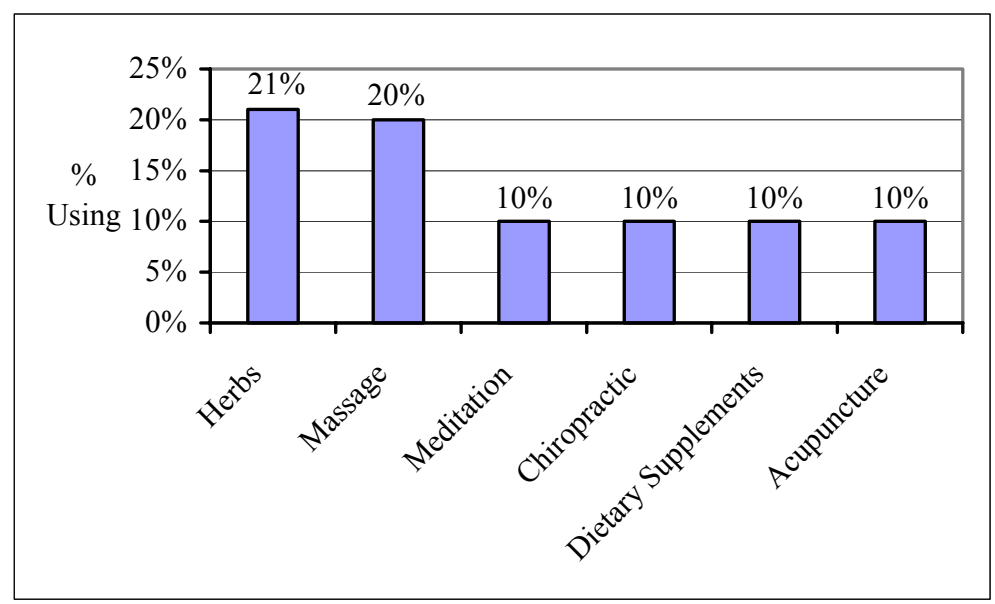

Figure 1

Most Commonly used Alternative Medical Therapies by 220 Health Education Instructors in 41 USA States

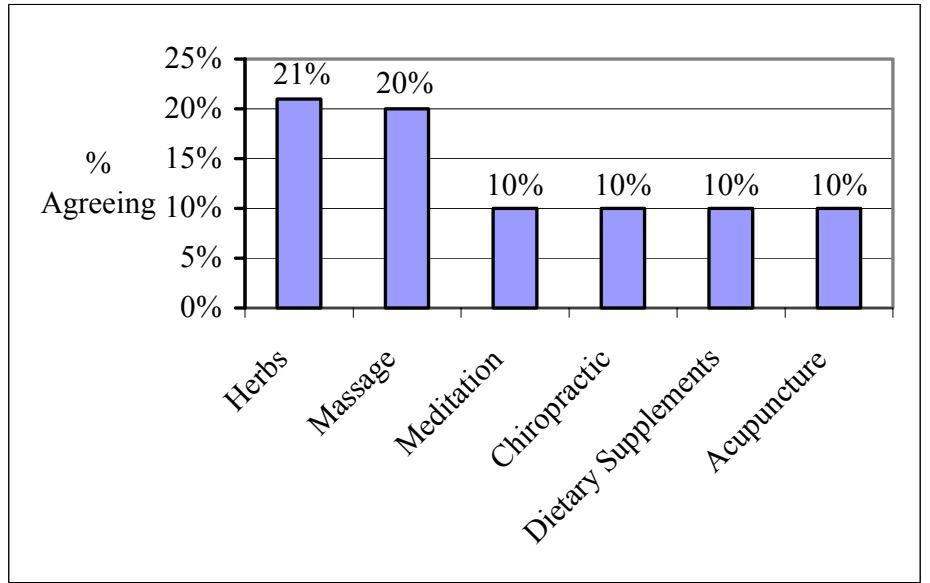

Figure 2

Specific Alternative Medical Therapies Meriting Closer Examination (Responses from 220 health education instructors from 41 US States)

When respondents were challenged concerning whether they would advocate for the use of untested or unproven therapies, $22 \%$ said that they would do so always or most of the time. In contradiction to this position, $93 \%$ of the sample stipulated that scientific evidence was very or somewhat important in their decision to support alternative medicine. Since only $7 \%$ did not agree with this position, there appears to be some cognitive dissonance among the other $15 \%$ who would advocate for untested or unproven therapies. This is a reminder to all health educators that the knowledge-behavior (or behavioral intention) relationship is tenuous at best.

Attitudes And Practices Regarding Science And Conventional Medicine

When asked how important scientific testing was for proposed new therapies, $90 \%$ of 
respondents answered that it was absolutely or usually essential. Ninety-five percent reported moderate to high levels of confidence in conventional medicine and $94 \%$ were very or somewhat satisfied with conventional medicine. This suggests that for most health educators, there is not a distinct choice between conventional and alternative medicine, rather a complementary relationship.

\section{Gender Differences}

There were some statistically significant gender differences present in this sample (see Table 2) with female respondents being significantly more likely to report a high level of confidence than males in conventional medicine and significantly more likely to advocate for, to use, and to be satisfied with alternative medicine. This view is consistent with several other recent studies (Cherniack, Senzel, \& Pan, 2001; Gotay, Hara, Issell, \& Maskarinec, 1999; Ni, Simile, \& Hardy, 2002). Males were significantly more likely to believe scientific evidence was essential for supporting alternative therapies but they were significantly less likely to report a high level of confidence in conventional medicine. Could this mean that males do not believe scientific evidence underlies conventional medicine? The fact that $97 \%$ of females and $92 \%$ of males reported moderate to high levels of confidence in conventional medicine pales when compared to the fact that $85 \%$ of females and $65 \%$ of males reported being satisfied or very satisfied with conventional medicine. It may be statistically significant that males were lower than females in confidence for conventional medicine, but there may be little practical significance associated with this difference.

It would be instructive to compare the results of this study with survey results of other health professionals regarding attitudes and practices related to alternative medicine as well as gender differences. Unfortunately, nearly all such surveys have widely divergent perspectives and questions. For example, Licensed Dietitians in
Oregon were questioned regarding perceived knowledge and attitudes regarding the effectiveness of functional foods, nutritional supplements, and herbs (Lee \& Georgiou, 2000). The majority of the dietitians in this study were confident of the effectiveness of functional foods and nutrient supplements for illness prevention and the treatment of chronic illness, and $50 \%$ were confident in the effectiveness of herbs. Nurses' perceptions of complementary and alternative medical therapies indicated that a randomly selected national sample of nurses perceived a preponderance of evidence supported the effectiveness of five therapies: biofeedback, chiropractic, meditation/relaxation, multi-vitamins, and massage therapy (Brolinson, Price, \& Ditmyer, 2001). A variety of studies (Ernst, Resch, \& White, 1995; Gordon, Sobel, \& Tarazona, 1998; Sikand, \& Laken, 1998) of physicians and allied medical personnel suggest that a large percentage (approximately 50\%) are interested in alternative medical therapies (definitions vary widely) with younger physicians better informed and more open to such therapies than their more skeptical older colleagues.

Our focus on gender differences in these analyses is based upon the predominance of females in baccalaureate level health education classes in the United States, many of whom find employment in helping agencies (Cancer Societies, Heart Associations, Family Planning and other reproductive health organizations) which have "front line" contact with the public. Findings from this study suggest that universitybased health instructors continue to incorporate scientific objectivity in their approach to developing curriculum content for CAM courses or electives. It is vital that students, many of whom are destined to become front-line health workers, receive objective, evidence-based perspectives on complementary and alternative medicine from their instructors, and be cognizant of the importance of applying the scientific method in health promotion and education.

\section{References}

American Association for Health Education. (1997). AAHE directory of institutions and graduate degree programs in health education, 1997 edition. Journal of Health Education, 28, 281-297. 
Astin, J. A. (1998). Why patients use alternative medicine. Journal of the American Medical Association, 279, 1548-1553.

Berman, B. M. (1998). Primary care physicians and complementary- alternative medicine: Training, attitudes, and practice patterns. Journal of the American Medical Association, 280, 272-281.

Brolinson, P. J., Price, J. H., Ditmyer, M. (2000). Nurses' perceptions of complementary and alternative therapies. Journal of Community Health, 26, 175-191.

Burstein, J., Gelber, S., Guadagnoli, E., et al. (1999). Use of alternative medicine by women with earlystage breast cancer. New England Journal of Medicine, 340, 1733-1738.

Cassiletth B. R. (1999). Complementary therapies: Overview and state of the art. Cancer Nursing, 22, 8590.

Cherniack, E., Senzel, R., \& Pan, C. (2001). Correlates of use of alternative medicine by the elderly in an urban population. Journal of Alternative and Complementary Medicine, 7, 277-280.

Easthope, B., Tranter, B., Gill, G. (2000). General practitioners attitudes toward complementary therapies. Social Science and Medicine, 5, 1555-1562.

Eisenberg, D. (2001). Long-term trends in the use of complementary and alternative medical therapies in the United States. Annals of Internal Medicine, 135, 262-268.

Eisenberg, D. M., Davis, R. B., Ettner, S. L., et al. (1998). Trends in alternative medicine use in the United States, 1990-1997. Journal of the American Medical Association, 280, 1569-1575.

Eisenberg, D. M., Kessler, \& R. C., Foster, C., Norlock, F., Calkins, D, \& Delbanco, T. (1993). Unconventional medicine in the United States. New England Journal of Medicine, 328, 246-252.

Elder, N., Gillcrist, A, \& Minz, R. (1997). Use of alternative health care by family practice patients. Archives of Family Medicine, 6, 181-184.

Ernst, E., Resch, K. L., \& White, A. R. (1995). Complementary medicine: What physicians think of it, a meta-analysis. Archives of Internal Medicine, 155, 2405-2409.

Fisher, P. \& Ward, A. (1994). Complementary medicine in Europe. British Medical Journal, 309, $107-$ 111.

Fontanarosa , P. B., \& Lundberg, G. D. (1998). Alternative medicine meets science. Journal of the American Medical Association, 280, 1618-1619.

Gordon, N. P., Sobel, D. S., Tarazona, E. Z. (1998). Use of an interest in alternative therapies among adult primary care clinicians and adult members in a large health maintenance organization. Western Journal of Medicine, 169, 153-162.

Gotay, C., Hara, W., Issell, B., \& Maskarinec, G. (1999). Use of complementary and alternative medicine in Hawaii cancer patients. Hawaii Medical Journal, 58, 94-98.

Grahame-Smith, D. (1995). Evidence based medicine: Socratic dissent. British Medical Journal, 310 , $1126-1127$.

Haynes, B. R. (1999). A warning to complementary medicine practitioners: get empirical evidence or else. British Medical Journal, 319, 1629 - 1632.

Kemper, K. J. (2001). Complementary and alternative medicine for children: Does it work? Archive of Diseases of Children, 84, 6-9.

Krauss, H., Godfrey, C., Kirk, J., \& Eisenberg, D. (1998). Alternative health care: Its use by individuals with physical disabilities. Archives of Physiological Medical Rehabilitation, 79, 1440-1447.

Langmead, L, Chitnis, M., \& Rampton, D. (2002). Use of complementary therapies by patients with IBD may indicate psychosocial distress. Inflammatory Bowel Disease, 8, 174-179.

Lee, Y., \& Georgiou, C. (2000). The knowledge, attitudes, and practices of dietitians licensed in Oregon regarding functional foods, nutrient supplements, and herbs as complementary medicine. Journal of the American Dietetic Association, 100, 543-548.

Murray, R. H. \& Rubel, A. J. (1992). Physicians and healers: Unwitting partners in health care. New England Journal of Medicine, 326, 61-64.

Ni, H., Simile, C., \& Hardy, A. (2002). Utilization of complementary and alternative medicine by United States adults: Results from the 1999 national health interview survey. Medical-Care, 40, 353-358. 
Ottolini, M., Hamburger, E., \& Loprieto, J. (1999). Alternative medicine use among children in the Washington, DC area. San Francisco, CA: Pediatric Academic Societies.

Patterson, S. M. \& Graf, H. M. (2000). Integrating complementary and alternative medicine into the health education curriculum. Journal of Health Education, 31, 346-351.

Rhee, D., Spaeth, G., Myers, J., Steinmann, W., Augsburger, J., Shatz, L., Terebuh, A., Ritner, J., \& Katz, L. (2002). Prevalence of the use of complementary and alternative medicine for glaucoma. Opthalmology, 109, 438-443.

Redwood, D. (2002). Methodological changes in the evaluation of complementary and alternative medicine: Issues raised by Sherman et al. and Hawk et al. The Journal of Alternative and Complementary Medicine, 8, 5-6.

Sackett, D. L., Rosenberg, W. M. C., Gray, J. A. M., Haynes, R. B., \& Richardson, W. S. (1996). Evidence-based medicine: What it is and what it isn't. British Medical Journal, 312, 71-72.

Segen, J. C. (1998). Dictionary of alternative medicine. Stamford, CT: Appleton.

Sikand, A., \& Laken, M. (1998). Pediatricians' experience with and attitudes toward complementary/alternative medicine. Archives of Pediatric and Adolescent Medicine, 152, 10591064.

Silverstein, D. D., \& Spiegel, A. D. (2001). Are physicians aware of the risks of alternative medicine? Journal of Community Health, 26, 159-165.

Vickers, A., \& Zolman, C. (1999). ABC of complementary medicine: Herbal medicine. British Medical Journal, 319, 1050-1053.

Weiss, S., Takakuwa, K., \& Ernst, A. (2001). Use, understanding, and belief about complementary and alternative medicines among emergency department patients. Academic Emergency Medicine, 8, 41-47.

Wetzel, M. S., Eisenberg, D. M. \& Kaptchuk, O. M. D. (1998). Courses involving complementary and alternative medicine at US medical schools. Journal of the American Medical Association, 280, 784-787.

Wilson, K., Mills, E., Ross, C, \& Guyatt, G. (2002). Teaching evidence-based complementary and alternative medicine. Journal of Alternative and Complementary Medicine, 8, 673-679.

Zolman, C., \& Vickers, A. (1999a). ABC of complementary medicine: Users and practitioners of complementary medicine. British Medical Journal, 319, 836-838.

Zolman, C., \& Vickers, A. (1999b). Complementary medicine in conventional practice. British Medical Journal, 319, 901-904.

Author Information

Roland Lamarine, HSD

Department of Health \& Community Services

College of Behavioral \& Social Sciences

California State University, Chico

Chico, CA 95929-0505

Phone: 530-898-6265

Fax: 530-898-5107

Email: rlamarine@,csuchico.edu

K. John Fisher, PhD

Oregon Research Institute, Eugene, Oregon

Vic Sbarbaro, EdD, CHES

Department of Health and Community Services

California State University, Chico 


\section{Appendix A \\ Alternative Medicine Survey \\ Health Educators' Attitudes \& Practices}

Dear Health Educator:

We are conducting a national survey regarding knowledge, attitudes, and practices of professional health educators in relation to alternative medicine. The results of this survey are confidential. There are no benefits or risks associated with participation in this study.

Alternative or complementary medicine encompasses a wide range of approaches including dietary supplements, herbs, biological agents, manual healing, bioelectromagnetics, mind-body interventions, and alternative medical practices. Alternative medicine includes therapies employed as part of conventional medicine and approaches that have been clearly exposed as fraudulent. Conventional medicine is defined as medical practices and procedures commonly employed by physicians and other certified health workers.

For this survey alternative medicine is:

"....a heterogeneous set of practices that are offered as an alternative to conventional medicine, for the preservation of health and the diagnosis and treatment of health related problems: its practitioners are often called healers." (New England Journal of Medicine, 1992, 326: 61)

1. In your capacity as a health educator, would you advocate for the use of alternative medicine (as defined above)?

\begin{tabular}{|l|l|}
\hline & Always \\
\hline & Sometimes \\
\hline & Rarely \\
\hline & Never \\
\hline
\end{tabular}

2. Have you personally used alternative medical therapies?

\begin{tabular}{|l|l|}
\hline & Yes \\
\hline & No \\
\hline & Don't remember \\
\hline
\end{tabular}

2 (a) If yes, please list the therapy(ies) have you employed and approximately how often you have used them. 
3. How important is scientific evidence (e.g., double blind placebo controlled studies) in your decision to support an alternative therapy?

\begin{tabular}{|l|l|}
\hline & Very important \\
\hline & Somewhat important \\
\hline & Minimally important \\
\hline & Not important \\
\hline
\end{tabular}

4. Would it be ethical for a health educator to advocate the use of an untested or unproven therapy?

\begin{tabular}{|l|l|}
\hline & Yes, always \\
\hline & Most of the time \\
\hline & Occasionally \\
\hline & Never \\
\hline
\end{tabular}

5. Which alternative therapies, if any, do you feel merit closer examination because there are indications that they may prove effective as a component of conventional medicine?

6. Are there any other approaches besides traditional scientific testing that should be employed in determining the efficacy of new or alternative therapies? Please explain.

7. In general, what is your level of confidence in scientifically tested conventional medicine? scientifically tested before being approved?

\begin{tabular}{|l|l|}
\hline & High level of confidence \\
\hline & Moderate level of confidence \\
\hline & Low level of confidence \\
\hline & No confidence \\
\hline
\end{tabular}

\begin{tabular}{|l|l|}
\hline & Absolutely essential \\
\hline & Usually essential \\
\hline & Sometimes essential \\
\hline & Seldom essential \\
\hline
\end{tabular}


9. In general, how would you rate your satisfaction with conventional medicine?

\begin{tabular}{|l|l|}
\hline & Very satisfied \\
\hline & Somewhat satisfied \\
\hline & Minimally satisfied \\
\hline & Not at all satisfied \\
\hline
\end{tabular}

10. How would you rate your personal experiences with alternative medicine?

\begin{tabular}{|l|l|}
\hline & Very satisfied \\
\hline & Somewhat satisfied \\
\hline & Minimally satisfied \\
\hline & Not at all satisfied \\
\hline $\begin{array}{l}\text { Have not had any experience } \\
\text { with alternative medicine }\end{array}$ \\
\hline
\end{tabular}

11. How would you describe your psychological health?

\begin{tabular}{|l|l|}
\hline & Very good \\
\hline & Good \\
\hline & Adequate \\
\hline & Poor \\
\hline
\end{tabular}

12. How would you describe your level of sexual satisfaction during the last year?

\begin{tabular}{|l|l|}
\hline & Very good \\
\hline & Good \\
\hline & Adequate \\
\hline & Poor \\
\hline & \\
\hline & Yes \\
\hline & No (skip to \#15) \\
\hline
\end{tabular}

14. If this illness is currently in remission (not active), how would you rate your fear of recurrence?

\begin{tabular}{|l|l|}
\hline & High \\
\hline & Moderate \\
\hline & Low \\
\hline & Very low \\
\hline & Not in remission \\
\hline
\end{tabular}

15. If you generally utilize both alternative and conventional medicine in your personal life, approximately what percent of the time do you employ alternative therapies?

Alternative medicine use $\%$

16. Which best describes your overall health status? conventional medicine $\%$

\begin{tabular}{|l|l|}
\hline & Excellent health \\
\hline & Moderately good health \\
\hline & Average health \\
\hline & Below average health \\
\hline & Poor health \\
\hline
\end{tabular}


17. How many times per week do you participate in at least 20 minutes of aerobic exercise vigorous enough to significantly raise your heart and breathing rate?

Times per week

18. What is your gender? Check one
a. Male [ ]
b. Female [ ]

19. What is your highest degree, discipline of the degree, and year granted?
Degree
Discipline
Year

20. How long have you worked as a health educator?

Years

Months

21. Please feel free to make any additional comments.

Thank you so much for completing this confidential survey. Confidentiality is assured. 


\section{Appendix B}

Alternative Medicine Survey

Health Students' Attitudes \& Practices

Dear Student:

We are conducting a survey regarding knowledge, attitudes, and practices of students in relation to alternative medicine. Participation in this survey is entirely voluntary and there are no benefits or risks associated with your participation. You may answer any or all of the questions and may withdraw, without penalty, from the survey at any time if you desire. This is an anonymous survey. The results will be reported as aggregated data, no individual information will be reported.

Alternative or complementary medicine encompass a wide range of approaches including dietary supplements, herbs, biological agents, manual healing, bioelectromagnetics, mind-body interventions, and alternative medical practices. Alternative medicine includes therapies employed as part of conventional medicine and approaches that have been clearly exposed as fraudulent. Conventional medicine is defined as medical practices and procedures commonly employed by physicians and other certified health workers.

For this survey alternative medicine is:

".....a heterogeneous set of practices that are offered as an alternative to conventional medicine, for the preservation of health and the diagnosis and treatment of health related problems: its practitioners are often called healers." (New England Journal of Medicine, 1992, 326:61)

1. Would you advocate for the use of alternative medicine (as defined above)?

\begin{tabular}{|l|l|}
\hline & Always \\
\hline & Sometimes \\
\hline & Rarely \\
\hline & Never \\
\hline
\end{tabular}

2. Have you personally used alternative medical therapies?

\begin{tabular}{|l|l|}
\hline & Yes \\
\hline & No \\
\hline & Don't remember \\
\hline
\end{tabular}

2 (a) If yes, please list the therapy(ies) you have employed and approximately how often you have used them. 
3. How important is scientific evidence (e.g. double blind placebo controlled studies) in your decision to support an alternative therapy?

4. Would it be ethical to advocate for the use of an untested or unproven therapy?

5. In general, what is your level of confidence in scientifically tested conventional medicine?

6. Is it essential that all proposed new therapies be scientifically tested before being approved?

7. In general, how would you rate your satisfaction with conventional medicine?

\begin{tabular}{|l|l|}
\hline & Very important \\
\hline & Somewhat important \\
\hline & Minimally important \\
\hline & Not important \\
\hline
\end{tabular}

\begin{tabular}{|l|l|}
\hline & Yes, always \\
\hline & Most of the time \\
\hline & Occasionally \\
\hline & Never \\
\hline
\end{tabular}

\begin{tabular}{|l|l|}
\hline & High level of confidence \\
\hline & Moderate level of confidence \\
\hline & Low level of confidence \\
\hline & No confidence \\
\hline
\end{tabular}

\begin{tabular}{|l|l|}
\hline & Absolutely essential \\
\hline & Usually essential \\
\hline & Sometimes essential \\
\hline & Seldom essential \\
\hline & Very satisfied \\
\hline & Somewhat satisfied \\
\hline & Minimally satisfied \\
\hline & Not at all satisfied \\
\hline
\end{tabular}


8. How would you rate your personal experiences with alternative medicine?

\begin{tabular}{|l|l|}
\hline & Very satisfied \\
\hline & Somewhat satisfied \\
\hline & Minimally satisfied \\
\hline & Not at all satisfied \\
\hline & $\begin{array}{l}\text { Have not had any experience with } \\
\text { alternative medicine }\end{array}$ \\
\hline
\end{tabular}

9. Within the last five years have you had any illnesses serious enough to cause you to miss significant time from school or work?

\begin{tabular}{|l|l|}
\hline & Yes \\
\hline & No (skip to \#11) \\
\hline
\end{tabular}

10. If this illness is currently in remission (not active), how would you rate your fear of recurrence?

\begin{tabular}{|l|l|}
\hline & High \\
\hline & Moderate \\
\hline & Low \\
\hline & Very low \\
\hline & Not in remission \\
\hline
\end{tabular}

11. Which best describes your overall health status?

\begin{tabular}{|l|l|}
\hline & Excellent health \\
\hline & Moderately good health \\
\hline & Average health \\
\hline & Below average health \\
\hline & Poor health \\
\hline
\end{tabular}

12. How many times per week do you participate in at least 20 minutes of aerobic exercise vigorous enough to significantly raise your heart and breathing rate?

times per week

13. What is your gender? Check one
a. Male $[$ ]
c. Female [ ] 
14. What is your year in school? (circle the correct choice)

Freshman Sophomore Junior Senior Grad Student Other

15. Have you taken a course on alternative medicine? (circle the correct choice)
Yes
No
Don't Know

16. Please feel free to make any additional comments.

Thank you so much for completing this anonymous survey.

For further information, you may contact Dr. Roland Lamarine at:

California State University, Chico, CA 95929-0505

(530) 898-6265 or email rlamarine@csuchico.edu 